\title{
Industrial funds flow freely
}

\section{Tokyo}

Although no one seems to have noticed, the latest budget figures from the Ministry of Education, Science and Culture (MESC) reveal that an astonishing change has taken place in Japan's universities.

Despite Japanese academics' vociferous insistence on their independence from Japan's industrial goals, the figures show that, in the coming year, funds provided by industry for research at universities will amount to $¥ 57,650$ million (\$461 million), a sum almost equal to the $¥$ million MESC plans to spend on research grants.

Almost 80 per cent of the money comes in the form of 'donations', which now total about $¥ 40,000$ million ( $\$ 320$ million) a year after a decade in which they have quadrupled. Growth is still at 20 per cent a year, far above the rate of inflation and the rate of increase of government funds. Most donations are in the form of private research grants for faculty members, according to Wataru Soga of the research cooperation division of MESC, but a small

\section{Scattered largesse}

\section{Tokyo}

A separate initiative by MESC to stimulate collaboration between industry and academic institutions is the 'regional joint research centre' scheme which is aimed at smaller, local universities in the remoter regions of Japan. Eighteen centres are now in place at universities in Kyushu, Hokkaido, and the main island of Japan. Five more will open next year.

The Cooperative Research Center of Kumamoto University in Japan's southern island of Kyushu, which was completed in 1988 at a cost of $¥ 500$ million ( $\$ 4$ million), is typical of the scheme.

Located in the Kumamoto 'technopolis', an industrial research park being promoted by the local prefectural government and the Ministry of International Trade and Industry (MITI), the centre has four permanent faculty members from Kumamoto University who are in charge of about 20 projects being carried out by graduate students and researchers from companies. The projects each have annual budgets of a few million yen and include such things as wind tunnel tests of skirts for hovercraft, investigation of chemical vapour deposition techniques to make high-temperature superconductors, and development of new high-speed imageprocessing systems.

It is too early to tell how successful the centre will be. But a recent tour revealed that the centre's small team of researchers have plenty of space and equipment.

David Swinbanks part is also used to establish chairs and new research divisions at the universities. The new Research Centre for Advanced Science and Technology at Tokyo University provides one example with eight research divisions funded by companies such as NEC, Nippon Telegraph and Telephone (NTT), Nippon Steel Corporation and Ricoh. Ten out of 24 of such new research divisions in Japan are headed by foreigners, employed on short-term (two-

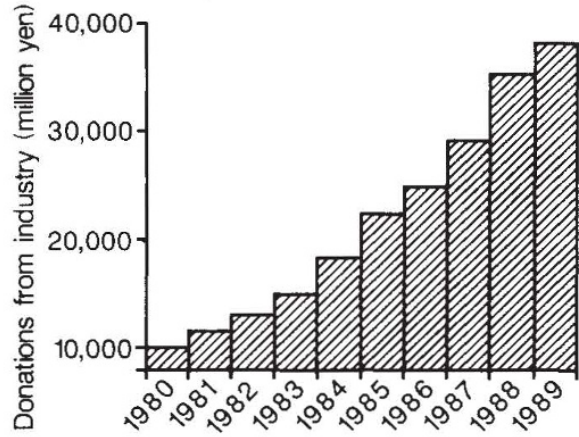

to five-year) contracts.

Although industrial funds may be large, they are not evenly distributed. Members of the faculty of science at Tokyo University say that, apart from their colleagues in computer science, the faculty benefits little from donations. Most of the money goes to the faculty of engineering and the faculty of medicine through connections with electronics and pharmaceutical companies. Personal relationships between powerful faculty members and companies are critical in determining who gets donations and a steady supply of bright young researchers is a reward for the donor company.

MESC has also put government money into schemes intended to encourage joint research between universities and industry. This year the programme contains 730 projects and costs $¥ 3,755$ million ( $\$ 30$ million). More than 80 per cent of the money comes from industry and the remainder from MESC. The universities provide the research facilities and the researchers. Industry is also able to carry out "commissioned" (jutaku) research, at universities in which it provides young researchers for specific projects. Industry provides all the funds and will spend $¥ 7,110$ million ( $\$ 57$ million) this year.

Despite the growth of industrial funds, much red tape remains. To obtain a small grant of $¥ 1$ million $(\$ 8,000)$ from a company, Shahid Siddiqui of the Laboratory of Molecular Biology of Toyohashi University of Technology first had to apply to the company for the grant and then "donate" it to the university.

Only after it was "officially" recognized by the university and MESC could he actually use the money for research, six months later.

David Swinbanks

\section{Still over the horizon}

\section{Washington}

IN spite of the increased availability of more effective methods of predicting or detecting genetic disease, a survey of US companies shows little change in the use of genetic testing in the workplace over the past seven years. More interestingly, the report*, released last week from the US Office of Technology Assessment (OTA) finds that fewer companies anticipate the future use of genetic testing than did in a similar earlier survey conducted in 1982 .

The OTA report surveyed 500 of the largest US corporations, the $\mathbf{5 0}$ largest utility companies and $\mathbf{3 3}$ major unions, in order to provide comparability with the 1982 survey. In addition, the scope of the survey was broadened to include smaller companies.

In the questionnaire, a distinction was made between genetic screening, which focuses on an individual's pre-existing genetic make-up and generally involves a one-time test to detect a single trait, and genetic monitoring, which requires multiple tests over time to determine the exposure of an individual to hazardous materials in the workplace.

OTA found that of the 330 (62.4 per cent) largest US companies that responded to the 1989 survey, 12 reported current use of genetic monitoring or screening programmes, and eight reported past use.

Similar results were found in the 1982 survey, where of the 366 ( 65.2 per cent) of companies that responded, six had active screening programmes and 12 reported past use. Of the companies with active programmes, testing involved cytogenetic monitoring and biochemical genetic screening. No companies reported the use of direct-DNA monitoring or screening.

The availability of these new technologies poses a real dilemma. While genetic monitoring and screening could yield useful long-range, predictive information about occupational health risks, the rights and responsibilities of job applicants, employees and employers are not well defined. Only a limited body of law deals specifically with genetic monitoring and screening in the workplace.

In a recent initiative, Representative John Conyers (Democrat, Michigan) introduced a bill, entitled the Human Genome Privacy Act, which would prevent the disclosure of genetic information by government agencies, contactors or grant recipients to third parties without the individual's consent (see Nature 347, $221 ; 1990)$. Although the bill does not encompass private industry, the bill's supporters believe that government should take the lead and set a standard by which companies should respond. Diane Gershon

* Genetic Monitoring and Screening in the Workplace. OTA BA-455 (Washington, DC: US Government Printing Office October 1990). 